\title{
Capital social y cultura, claves esenciales del desarrollo
}

\section{Bernardo Kliksberg}

Coordinador del Instituto Interamericano para el Desarrollo Social (INDES) del Banco Interamericano de Desarrollo
En este artículo se exploran las posibilidades que tienen el capital social y la cultura de aportar al desarrollo económico y social. El trabajo se centra particularmente en la situación de América Latina, una región con graves problemas de pobreza, que afectan a vastos sectores de la población, y de falta de equidad, que han llevado a que se le considere el continente con mayor desigualdad. Se argumenta aquí que, si bien es cierto que la integración de los temas del capital social y la cultura a las discusiones sobre el desarrollo hace más compleja la búsqueda de estrategias y diseños adecuados, también lo es que las políticas basadas en diseños que marginan tales aspectos han demostrado tener profundas limitaciones. En el artículo se indaga en primer lugar en la idea de capital social, haciendo hincapié no en el análisis teórico, sino en la presencia concreta de este capital en realidades actuales. Luego se examina el capital social en acción en casos latinoamericanos y, por último, se formulan algunas reflexiones sobre los posibles aportes de la cultura al desarrollo latinoamericano. 


\section{I \\ El nuevo debate sobre el desarrollo}

A fines del siglo XX la humanidad cuenta con inmensas fuerzas productivas. Las revoluciones tecnológicas en curso han alterado sustancialmente sus capacidades potenciales de generar bienes y servicios. Los avances simultáneos en campos como la informática, la biotecnología, la robótica, la microelectrónica, las telecomunicaciones, la ciencia de los materiales y otras áreas, han determinado rupturas cualitativas en las posibilidades de producción, ampliándolas extensamente. Sin embargo, 1300 millones de personas carecen de lo más mínimo y viven en pobreza extrema con menos de un dólar de ingresos al día, 3000 millones se hallan en pobreza, teniendo que subsistir con menos de dos dólares diarios, 1300 millones de personas carecen de agua potable, 3000 millones no tienen instalaciones sanitarias básicas y 2000 millones no reciben electricidad.

Alcanzar la deseada meta de desarrollo económico y social es más viable que nunca en términos de tecnologías y potencial productivo, pero al mismo tiempo el objetivo se halla muy distante de amplias poblaciones en diversos continentes, y entre ellos, en América Latina.

La "aldea global" en que se ha convertido el planeta, en donde las interrelaciones de los países y los mercados se multiplican continuamente, parece caracterizarse por una explosión de complejidad, direcciones contradictorias de evolución y altas dosis de incertidumbre. Ilya Prigogine, Premio Nobel de Química, ha señalado que la mayor parte de las estructuras de la realidad actual son "estructuras disipativas de final abierto"; es difícil predecir en qué sentido evolucionarán, y las lógicas tradicionales son impotentes para explicar su curso (Prigogine, 1993). Por su parte, Morín (1991) resalta que en lugar del "fin de la historia" - vaticinado por algunos que alegaron que al desaparecer el mundo bipolar la historia sería previsible y hasta "aburrida" - lo que tenemos ante nuestros ojos es que "de aquí en adelante el futuro se llama incertidumbre".

La historia en curso está marcada por severas contradicciones. Así, en tanto que el conocimiento tecnológico disponible ha multiplicado las capacidades de

$\square$ Las opiniones expresadas en este trabajo son de responsabilidad del autor y no representan necesariamente las de la institución en la que se desempeña. dominar la naturaleza, el ser humano está creando desequilibrios ecológicos de gran magnitud y poniendo en peligro aspectos básicos del ecosistema y su propia supervivencia. Mientras las capacidades productivas han llevado la producción mundial a más de 25 trillones de dólares, las polarizaciones sociales se han agudizado fuertemente $y$, según los informes de las Naciones Unidas (PNUD, 1998b), 358 personas poseen una riqueza acumulada superior a la del $45 \%$ de la población mundial. Las disparidades alcanzan los aspectos más elementales de la vida cotidiana. Los acelerados progresos en medicina han permitido una prolongación considerable de la esperanza de vida, pero mientras en las 26 naciones más ricas ésta era de 78 años en 1997, en los 46 países más pobres no superaba los 53 años. La idea del progreso indefinido está siendo suplantada por visiones que asignan un papel mayor a las complejidades, las contradicciones y las incertidumbres.

En este marco general, hay un nuevo debate sobre los modelos de desarrollo en activa ebullición. Buscando caminos más eficaces, en un mundo donde la vida cotidiana de amplios sectores está agobiada por carencias agudas, y donde se estima que una tercera parte de la población activa mundial se halla afectada por severos problemas de desocupación y subocupación, se están revisando supuestos no convalidados por los hechos e integrando variables a las que se asignaba escaso peso.

Por las realidades descritas en párrafos anteriores, vemos que no se han cumplido los pronósticos de que, aplicando las recetas del pensamiento económico convencional, se obtendría progreso económico estable y retrocederían la pobreza y la inequidad en el mundo en desarrollo. Frente a esta situación se escuchan voces muy autorizadas que reclaman un reexamen profundo de ese pensamiento. Entre ellas, el premio Nobel de Economía 1998, Amartya Sen, cuestiona la vía usualmente pregonada para el desarrollo, que describe como "de sangre, sudor y lágrimas", calificándola como una "política cruel de desarrollo", que al mismo tiempo es altamente ineficiente (Sen, 1997b). Joseph Stiglitz, ex jefe de los asesores económicos del Presidente Clinton, aboga por un consenso post Washington que revise las metas y los instrumentos de dicho consenso, y resalta que "la experiencia latinoamericana sugiere que deberíamos reexaminar, rehacer y ampliar los conocimientos acerca de la economía de de- 
sarrollo, que se toman como verdad" (Stiglitz, 1998). James Wolfensohn, presidente del Banco Mundial, plantea que "sin desarrollo social paralelo no habrá desarrollo económico satisfactorio" (Wolfensohn, 1996). Diversas líneas de investigación recientes concluyen que es imprescindible superar los reduccionismos de corte economicista e incluir en la reflexión sobre el desarrollo las dimensiones políticas, institucionales y culturales. Por su parte, Enrique V. Iglesias, presidente del BID, señala que "el desarrollo sólo puede encararse en forma integral; los enfoques monistas sencillamente no funcionan" (Iglesias, 1997a).
Este marco de agitado debate sobre la validez del pensamiento económico convencional ha generado condiciones propicias para instalar un área de análisis en continuo crecimiento alrededor de la idea de "capital social". Uno de los focos de ese análisis es el reexamen de las relaciones entre cultura y desarrollo.

El presente trabajo examina las relaciones entre capital social y diversas dimensiones del desarrollo; presenta experiencias latinoamericanas de movilización del capital social e indaga finalmente en algunos de los posibles aportes de la cultura a los esfuerzos de desarrollo económico y social.

\section{II}

\section{Capital social, cultura y desarrollo}

El Banco Mundial distingue cuatro formas básicas de capital: i) el natural, constituido por la dotación de recursos naturales con que cuenta un país; ii) el construido, generado por el ser humano, que incluye infraestructura, bienes de capital, capital financiero, comercial, etc.; iii) el capital humano, determinado por los grados de nutrición, salud y educación de la población; y iv) el capital social, descubrimiento reciente de las ciencias del desarrollo. Algunos estudios adjudican a las dos últimas formas de capital un porcentaje mayoritario del desarrollo económico de las naciones a fines del siglo XX, e indican que allí hay claves decisivas del progreso tecnológico, la competitividad, el crecimiento sostenido, el buen gobierno y la estabilidad democrática.

¿Qué es en definitiva el capital social? Aún no se tiene una definición que genere consenso. De reciente exploración, el concepto está aún en plena delimitación de su identidad. Sin embargo, pese a considerables imprecisiones, hay la impresión cada vez más generalizada de que, al investigarlo, las disciplinas del desarrollo están incorporando al conocimiento y a la acción un amplísimo número de variables importantes que estaban fuera del encuadre convencional.

Robert Putnam, precursor de los análisis del capital social, expresa en su difundido estudio sobre las disimilitudes entre la Italia septentrional y la Italia meridional que este capital está conformado fundamentalmente por el grado de confianza existente entre los actores sociales de una sociedad, las normas de comportamiento cívico practicadas y el nivel de asociatividad (Putnam, 1994). Estos elementos muestran la riqueza y fortaleza del tejido social. La confianza, por ejemplo, actúa como un "ahorrador de conflictos potenciales", limitando el "pleitismo". Las actitudes positivas en materia de comportamiento cívico, que van desde el cuidado de los espacios públicos al pago de los impuestos, contribuyen al bienestar general. La existencia de altos niveles de asociatividad en una sociedad indica que ésta tiene capacidades para actuar en forma cooperativa, armando redes, concertaciones y sinergias de todo orden. Estos factores tendrían, según Putnam, mayor presencia y profundidad en el norte de Italia que en el sur de este país, y habrían tenido un papel decisivo en el mejor desempeño económico, mayor calidad de gobierno y más estabilidad política en la Italia septentrional.

Para otro de los precursores, James Coleman, el capital social se presenta tanto en el plano individual como en el colectivo. El primero tiene que ver con el grado de integración social de un individuo y con su red de contactos sociales; implica relaciones, expectativas de reciprocidad y comportamientos confiables, y mejora la eficacia privada. Pero también es un bien colectivo. Por ejemplo, si todos en un vecindario siguen normas tácitas de preocupación por los demás y de no agresión, los niños podrán caminar a la escuela con seguridad y el capital social estará produciendo orden público (Coleman, 1990).

Los diversos analistas hacen hincapié en distintos aspectos. Así, Newton (1997) opina que el capital social puede ser visto como un fenómeno subjetivo, compuesto de valores y actitudes que influyen en la forma en que se relacionan las personas. Incluye confianza, normas de reciprocidad, actitudes y valores que ayudan a la gente a superar relaciones conflictivas y 
competitivas para establecer lazos de cooperación y ayuda mutua. Baas (1997) dice que el capital social tiene que ver con cohesión social e identificación con las formas de gobierno y con expresiones culturales y comportamientos sociales que hacen que la sociedad sea más cohesiva y represente más que una suma de individuos. Considera que los arreglos institucionales horizontales tienen un efecto positivo en la generación de redes de confianza, buen gobierno y equidad social y que el capital social contribuye de manera importante a estimular la solidaridad y a superar las fallas del mercado a través de acciones colectivas y del uso comunitario de recursos. Joseph (1998) percibe este capital como un vasto conjunto de ideas, ideales, instituciones y arreglos sociales, a través de los cuales las personas encuentran su voz y movilizan sus energías particulares para causas públicas. Bullen y Onyx (1998) lo ven como redes sociales basadas en principios de confianza, reciprocidad y normas de acción.

En una visión crítica, Levi (1996) destaca la importancia de los hallazgos de Putnam, pero cree que es necesario hacer más hincapié en las vías por las que el Estado puede favorecer la creación de capital social. Considera que el interés de Putnam por las asociaciones civiles, alejadas del Estado, deriva de su perspectiva romántica de la comunidad y del capital social. Ese romanticismo restringiría la identificación de mecanismos optativos para la creación y uso del capital social, y limitaría las conceptualizaciones teóricas. Wall, Ferrazzi y Schryer (1998) entienden que la teoría del capital social necesita de mayores refinamientos antes de que pueda ser considerada una generalización medible. Serageldin (1998) resalta que, pese a haber consenso en que el capital social es relevante para el desarrollo, no hay acuerdo entre los investigadores y los cientistas prácticos acerca de los modos particulares en que hace su aporte, cómo se le puede generar y utilizar y de qué modo se le puede materializar y estudiar empíricamente.

Mientras prosigue el debate epistemológico y metodológico - totalmente legítimo- dada la enorme complejidad del tema y el hecho de que los estudios sistemáticos sobre él se iniciaron hace menos de una década-, el capital social sigue dando muestras de su presencia y acción efectiva. En esto queremos concentrarnos.

Una amplia línea de investigaciones enfocadas a "registrarlo en acción" está arrojando continuamente nuevas pruebas del peso del capital social en el desarrollo. Así, Knack y Keefer (1997) midieron econométricamente las correlaciones entre confianza y normas de cooperación cívica, por un lado, y crecimiento económico, por otro, en un amplio grupo de países y encontraron que las primeras tienen un fuerte impacto sobre el segundo. Asimismo, su estudio indica que el capital social integrado por esos dos componentes es mayor en sociedades menos polarizadas en materia de desigualdad y de diferencias étnicas.

Narayan y Pritchet (1997) realizaron un estudio muy sugerente sobre grado de asociatividad y rendimiento económico en hogares rurales de Tanzania. Descubrieron que aun en esos contextos de gran pobreza las familias con mayores niveles de ingresos eran las que tenían un más alto grado de participación en organizaciones colectivas, y el capital social que acumulaban a través de esa participación las beneficiaba individualmente y creaba beneficios colectivos por diversas vías. Estas familias: i) utilizaban prácticas agrícolas mejores que las de los hogares que no participaban, ya que al participar recibían información que las llevaba a utilizar más agroquímicos, fertilizantes y semillas mejoradas; ii) tenían mejor información sobre el mercado; iii) estaban dispuestas a tomar más riesgos, porque el formar parte de una red social las hacía sentirse más protegidas; iv)influían en el mejoramiento de los servicios públicos y participaban más en la escuela, y v) cooperaban más a nivel del municipio. Señalan estos investigadores en sus conclusiones que los canales identificados por los que el capital social incrementaba los ingresos, y la solidez econométrica de la magnitud de sus efectos, sugieren que el capital social es capital y no meramente un bien de consumo.

La Porta, López de Silanes, Shleifer y Vishny (1997) trataron de convalidar las tesis de Putnam en una muestra amplia de países. Sus análisis estadísticos arrojan significativas correlaciones entre el grado de confianza existente en una sociedad y factores como la eficiencia judicial, la ausencia de corrupción, la calidad de la burocracia y el cumplimiento de las obligaciones tributarias. Consideran que los resultados de Putnam para Italia aparecen confirmados a nivel internacional.

Teachman, Paasch y Carver (1997) trataron de medir cómo influye el capital social en el rendimiento educativo de los niños. Utilizaron tres indicadores: la dinámica de la familia, los lazos con la comunidad y el número de veces que un niño ha cambiado de colegio. Encontraron fuerte correlación con un indicador clave de rendimiento, la probabilidad de deserción. Su hipótesis es que el capital social hace más productivas otras formas de capital, como el humano y el financiero. 
La influencia positiva de un componente central del capital social, la familia, en numerosos aspectos ha sido verificada por diversas investigaciones recientes. Cuanto mayor es la solidez de ese capital social básico mejores son los resultados, y al revés. Una amplia investigación sobre 60000 niños en Estados Unidos (Wilson, 1994) indica que los niños que vivían con un solo progenitor eran dos veces más propensos a ser expulsados o suspendidos en la escuela, a sufrir problemas emocionales o de conducta y a tener dificultades con los compañeros. También eran mucho más proclives a tener una conducta antisocial. Katzman (1997) señala que, según estudios realizados en el Uruguay, entre los hijos concebidos fuera del matrimonio la mortalidad infantil es mucho mayor y que los que no conviven con ambos padres biológicos exhiben mayores daños en distintas dimensiones del desarrollo psicomotriz. Una investigación en Suecia -en un medio totalmente diferente y con mucho mejores condiciones económicas - comprueba que las familias estables influyen positivamente en el rendimiento del niño. Jonsson y Gahler (1997) demuestran que los niños que vienen de familias divorciadas muestran menor rendimiento educativo. Hay una pérdida de recursos en relación a aquéllos con los que cuenta el niño en las familias estables.

Sanders y Nee (1996) analizan la familia como capital social en el caso de los inmigrantes en los Estados Unidos. Sus estudios indican que el espacio familiar crea condiciones que hacen factible una estrategia clave de supervivencia entre los inmigrantes: el autoempleo. La familia minimiza los costos de producción, transacción e información asociados con él. Se facilita así la aparición de empresas operadas familiarmente. Hagan, MacMillan y Wheaton (1996) señalan que en las migraciones, incluso hacia el interior de un país, hay pérdidas de capital social, y que ellas son menores en familias con padres involucrados con los niños y con madres protectoras, y mayores si los padres y madres no se dedican intensamente a los niños.

Kawachi, Kennedy y Lochner (1997) dan cuenta de datos muy decidores sobre la relación entre capital social, equidad y salud pública. El conocido estudio de Alameda County, confirmado después en investigaciones epidemiológicas en diferentes comunidades, descubrió que las personas con menos contactos sociales tienen peores probabilidades en términos de esperanza de vida que aquellos con contactos más amplios. Por lo tanto, la cohesión social de una sociedad que facilita los contactos interpersonales es un factor fundamental de salud pública. Los autores midieron estadísticamente las correlaciones entre el capital social representado por la confianza, por un lado, y la mortalidad, por otro, en 39 estados de los Estados Unidos. Observaron que cuanto menor era el grado de confianza entre los ciudadanos, mayor era la mortalidad media. La misma correlación se tuvo al relacionar la tasa de participación en asociaciones voluntarias con la mortalidad: cuanto más baja era la primera, más crecía la segunda. Los investigadores introdujeron en el análisis el grado de desigualdad económica y verificaron que cuanto más alto era éste, menor era la confianza que unos ciudadanos tenían en otros. El modelo estadístico que utilizaron les permitió afirmar que, por cada punto que aumentaba la desigualdad en la distribución de los ingresos, la mortalidad subía dos o tres puntos con respecto a lo que debiera haber sido. Para ilustrar su análisis, los autores usaron diversas cifras comparadas. Estados Unidos, a pesar de tener uno de los ingresos per cápita más altos del mundo, acusaba en 1993 un ingreso per cápita de 24680 dólares y una esperanza de vida de 76.1 años, inferior esta última a la de naciones con menor ingreso, como los Países Bajos (17 340 dólares y 77.5 años), Israel (15 130 dólares y 76.6 años) y España (13 660 dólares y 77.7 años). Cabe aseverar entonces que una distribución más igualitaria de los ingresos crea mayor armonía y cohesión social y mejora la salud pública. Las sociedades con mayor esperanza de vida en el mundo, como Suecia (78.3 años) y Japón (79.6 años) se caracterizan por muy altos niveles de equidad. La desigualdad, concluyen los investigadores, hace disminuir el capital social, y ello afecta fuertemente la salud de la población.

El capital social, al margen de las especulaciones y las búsquedas de precisión metodológica, desde ya válidas y necesarias, de hecho opera a diario y tiene gran peso en el proceso de desarrollo. Hirschman (1984), en forma pionera, ha planteado al respecto algo que merece toda nuestra atención. Indica que el capital social es la única forma de capital que no disminuye o se agota con su uso sino que, por el contrario, crece con él. Señala: 'El amor o el civismo no son recursos limitados o fijos, como pueden ser otros factores de producción; son recursos cuya disponibilidad, lejos de disminuir, aumenta con su empleo'.

El capital social puede, asimismo, ser reducido o destruido. Moser (1998) advierte sobre la vulnerabilidad de la población pobre en capital social frente a las crisis económicas: 'mientras que los hogares con suficientes recursos mantienen relaciones recíprocas, aque- 
llos que enfrentan la crisis se retiran de tales relaciones ante su imposibilidad de cumplir sus obligaciones'. Fuentes (1998) analiza cómo en Chiapas (México) las poblaciones campesinas que se vieron obligadas a migrar se descapitalizaron severamente en términos de capital social, dado que se destruyeron sus vínculos e inserciones básicas. Por otro lado, como lo señalan varios estudios, puede haber formas de capital social negativo, como las organizaciones criminales, pero su existencia no invalida las inmensas potencialidades del capital social positivo.

La cultura cruza todas las dimensiones del capital social de una sociedad. La cultura subyace los componentes básicos considerados capital social, como la confianza, el comportamiento cívico, el grado de asociatividad. Las relaciones entre cultura y desarrollo son de todo orden, y asombra la escasa atención que se les ha prestado. Aparecen potenciadas al revalorizarse todos estos elementos silenciosos e invisibles, pero claramente operantes, involucrados en la idea de capital social.

Entre otros aspectos, los valores de que es portadora una sociedad van a incidir fuertemente sobre los esfuerzos de desarrollo. Como lo ha señalado Sen (1997a), 'los códigos éticos de los empresarios y profesionales son parte de los recursos productivos de la sociedad'. Si estos códigos subrayan valores afines al proyecto de desarrollo con equidad reclamado por amplios sectores de la población, lo favorecerán; de lo contrario, lo obstaculizarán.

Los valores predominantes en el sistema educativo, en los medios de difusión y en otros ámbitos influyentes de la formación de valores pueden estimular u obstruir la conformación de capital social, el que a su vez, como se ha visto, tiene efectos de importancia sobre el desarrollo. Chang (1997) subraya que los valores ponen las bases de la preocupación del uno por el otro más allá del solo bienestar personal y contribuyen de manera crucial a determinar si habrá avances en las redes sociales, las normas y la confianza. Valores que tienen sus raíces en la cultura y son fortalecidos o dificultados por ella, como la solidaridad, el altruismo, el respeto y la tolerancia, son esenciales para un desarrollo sostenido.

En la lucha contra la pobreza la cultura aparece como un elemento clave. Como lo destaca la UNESCO (1996): "Para los pobres los valores propios son frecuentemente lo único que pueden afirmar". Los grupos desfavorecidos tienen valores que les dan identidad. El irrespeto a estos grupos y su marginación pueden ser totalmente lesivos a su identidad y bloquear las mejores propuestas productivas. Por el contrario, su potenciación y afirmación pueden desencadenar enormes energías creativas.

La cultura es, asimismo, un factor decisivo de cohesión social. En ella las personas pueden reconocerse mutuamente, crecer en conjunto y desarrollar la autoestima colectiva. Como señala al respecto Stiglitz (1998), preservar los valores culturales tiene gran importancia para el desarrollo, por cuanto ellos sirven como una fuerza cohesiva en una época en que muchas otras se están debilitando.

El capital social y la cultura pueden ser palancas formidables de desarrollo si se crean las condiciones adecuadas. Su desconocimiento o destrucción, por el contrario, dificulta enormemente el camino. Cabría preguntarse, sin embargo, si potenciarlos no pertenecerá al reino de las grandes utopías, de un porvenir todavía ajeno a las posibilidades actuales de las sociedades. En la sección siguiente se intenta demostrar que esto no es así, que hay experiencias concretas que han logrado utilizar tales palancas en escala considerable al servicio del desarrollo y que es preciso extraer enseñanzas de ellas.

\section{III}

\section{El capital social en acción. Experiencias latinoamericanas}

¿Qué sucede cuando se realiza en forma sostenida un trabajo de largo plazo para movilizar aspectos claves del capital social de una comunidad? ¿Cuáles son las respuestas observables? ¿Qué oportunidades nuevas y qué dificultades aparecen? Existe una amplísima gama de experiencias en curso a nivel internacional que pueden proporcionar indicios significativos al respecto. Algunas han obtenido celebridad mundial, como la del 
Grameen Bank de Bangladesh, dedicada a apoyar financieramente a campesinos pobres, que ha logrado sorprendentes resultados apoyándose en elementos que tienen que ver con el grado de asociatividad y de confianza mutua, y otras dimensiones del capital social. Aquí nos concentraremos en experiencias de América Latina, que son indicativas del potencial latente en la región en esta materia. Hemos escogido tres casos que han obtenido resultados de alta relevancia, que son reconocidos en sus países y a nivel internacional como "prácticas sociales de gran éxito" y que son continuamente analizados y visitados para ver si es posible imitarlos total o parcialmente.

\section{Villa El Salvador (Perú): de los arenales a una experiencia social de avanzada}

En 1971 varios centenares de personas pobres invadieron tierras públicas en las afueras de Lima. Se les sumaron miles de habitantes de tugurios de esta ciudad. El gobierno intervino para expulsarlos, y finalmente accedió a que se radicaran en un vasto arenal ubicado a $19 \mathrm{~km}$ de Lima. Esos 50000 pobres, que carecían de recursos de toda índole, fundaron allí Villa El Salvador. Se les fueron agregando muchas más personas y su población actual se estima cercana a los 300000 habitantes. Esta experiencia es considerada muy particular en múltiples aspectos. El plano urbanístico trazado diferencia netamente a Villa El Salvador de otras barriadas pobres. El diseño es el de 1300 manzanas, que configuran 110 grupos residenciales. En lugar de haber un solo centro en donde funcionen los edificios públicos básicos, el esquema es totalmente descentralizado. Cada grupo residencial tiene su propio centro, con locales comunales y espacios para el deporte, las actividades culturales y el encuentro social. Esto favoreció la interacción y maximizó las posibilidades de cooperación. Se dio así un modelo organizativo basado en la participación activa. Partiendo de delegados por manzana y por grupos residenciales, los habitantes de Villa El Salvador crearon una organización, CUAVES, que representa a toda la comunidad y que ha tenido un peso decisivo en su desarrollo. Establecieron casi 4000 unidades organizativas para buscar soluciones y gestionar los asuntos comunitarios, en las que participa la gran mayoría de la población: cerca del 50\% de los mayores de 18 años ocupan algún cargo directivo en ellas.

En estos arenales, carentes de todo orden de recursos y casi incomunicados (debían recorrer $3 \mathrm{~km}$ para encontrar una vía de acceso a Lima), los pobladores desplegaron un gigantesco esfuerzo de construcción, basado principalmente en el trabajo voluntario de la misma comunidad. Un inventario de la situación de fines de 1989 dice que, en menos de dos décadas, tenían 50000 viviendas, 38000 de ellas construidas por ellos mismos - un $68 \%$ con materiales nobles como ladrillo, cemento, techos de concreto, etc.-, habían levantado con su esfuerzo $2800000 \mathrm{~m}^{2}$ de calles de tierra afirmada, y habían construido, en su mayor parte con los recursos y el trabajo de la comunidad, 60 locales comunales, 64 centros educativos y 32 bibliotecas populares. A ellos se sumaban 41 núcleos de servicios integrados de salud, educación y recuperación nutricional, centros de salud comunitarios, una red de farmacias, y una razonable estructura vial interna con cuatro rutas principales y siete avenidas perpendiculares. Además, habían plantado medio millón de árboles.

Los logros sociales de la Villa El Salvador -mientras permanecía pobre y con serios problemas ocupacionales, como toda Lima- eran también muy significativos. La tasa de analfabetismo había descendido de 5.8 a $3.5 \%$. La tasa de matrícula en la educación primaria había alcanzado al $98 \%$ y en la secundaria a más de $90 \%$, todas cifras superiores a los promedios nacionales y mucho mejores que las de poblaciones pobres similares. En salud, las campañas de vacunación realizadas con apoyo de la comunidad, que habían cubierto a toda la población, así como la organización de la comunidad para la salud preventiva y el control de embarazos, habían incidido en un fuerte descenso de la mortalidad infantil (a 67 por mil, contra un promedio nacional de 88 , a 95 por mil). La mortalidad general era también inferior a los promedios nacionales. Se registraban asimismo avances en materia de obtención de servicios de agua, desagüe y electricidad, en un plazo que se estimó menor en 8 años al que tardaban otros barrios pobres en lograrlos, y se habían desarrollado considerables infraestructura, equipamiento y servicios comunitarios, superiores a los de otras barriadas.

El enorme esfuerzo colectivo realizado ha sido descrito por el varias veces alcalde de Villa El Salvador, Michel Azcueta (Zapata, 1996), del siguiente modo: "El pueblo de Villa El Salvador, con su esfuerzo y su lucha, ha ido construyendo una ciudad de la nada, con cientos de kilómetros de redes de agua y de luz, pistas, colegios, mercados, zona agropecuaria, y hasta un parque industrial, conseguido también con lucha por los pequeños industriales de la zona”. 
Se plantea una pregunta de fondo: ¿cómo fue posible lograr estos resultados partiendo de la miseria, en un marco natural tan desfavorable, en medio de la aguda crisis económica que vivió el Perú, como toda la región, en los años ochenta, y de todo orden de dificultades? Las claves para entender los logros —que no erradicaron la pobreza, pero sí mejoraron aspectos fundamentales de la vida de sus habitantes y la convirtieron en una barriada pobre diferente- parecen hallarse en elementos incluidos en el concepto de capital social.

La población originaria de Villa El Salvador estaba conformada, en su mayor parte, por familias llegadas de la sierra peruana. Los campesinos de los Andes carecían de toda riqueza material, pero tenían un rico capital social. Llevaban consigo la cultura y la tradición indígenas, y una milenaria experiencia histórica de cooperación, trabajo comunal y solidaridad. En la Villa se aplicaron aspectos centrales de esa cultura, como la práctica de una intensa vida comunitaria y la coexistencia de la propiedad comunal de servicios útiles para todos con la propiedad familiar e individual. Esa cultura facilitó el montaje de esta extensa organización participativa, en la cual todos los pobladores fueron convocados a ser actores de las soluciones de los problemas colectivos, y que funcionó con fluidez en virtud de las bases históricas favorables que había en la cultura campesina peruana. Hasta antiguas recetas técnicas, como las lagunas de oxidación utilizadas por los Incas, fueron empleadas intensamente: los desechos se procesaban mediante un sistema de lagunas que llevaba a la producción de abonos, usados después para generar zonas verdes y producción agrícola.

La importancia del trabajo colectivo como medio para buscar soluciones, visión anclada en la cultura de los pobladores, impregnó desde el inicio la historia de la Villa. Se refleja vívidamente en cómo se enfrentó el problema de construir escuelas. Michel Azcueta narra: “... desde la instalación misma, la población se organizó para que se construyeran escuelas y los niños no perdieran el año escolar. Se formaron doce comités pro escuela en los primeros tres meses y se inició la construcción de muchas aulas en un esfuerzo que, mirado a la distancia, parece enorme y que no se entiende sin acudir a una explicación sobre sus motivaciones subjetivas. Se empezó a dictar clases en aulas que usaban esteras como paredes, las que se impermeabilizaban con plásticos para mínimamente combatir el frío invernal, mientras que el suelo era de tierra apenas afirmada, y los escasos ladrillos fueron reservados para ser usados como precarios bancos por los niños. Estas aulas fueron construidas en jornadas colectivas dominicales, con un entusiasmo y febrilidad que han dejado un recuerdo imborrable entre sus protagonistas" (Zapata, 1996).

Favorecido por estas condiciones se creó en la Villa un amplio y sólido tejido asociativo. Se constituyeron organizaciones de jóvenes, de mujeres, de madres, cooperativas de mercados, asociaciones de pequeños industriales y comerciantes, rondas urbanas, coordinadoras y brigadas juveniles, ligas deportivas, grupos culturales de todo orden. La asociatividad cubrió allí los más variados aspectos: productores que se unieron para comprar insumos en conjunto, buscar mancomunadamente maquinarias, mejorar la calidad; más de un centenar de clubes de madres, que crearon y gestionaron ejemplarmente 264 comedores populares y 150 programas de vaso de leche; jóvenes que dirigieron y llevaron adelante centenares de grupos culturales, artísticos, bibliotecas populares, clubes deportivos, asociaciones estudiantiles y talleres de comunicación.

El trabajo de la propia comunidad, organizada en marcos cabalmente participativos, estuvo en la base de los avances que se fueron logrando en corto tiempo. El proceso "disparó" el capital social latente, que se fue multiplicando. La creación, a partir de la nada, de un municipio entero por su población, generó una identidad sólida e impulsó la autoestima personal y colectiva. Como señala Franco (1992), la ciudad que se creó fue la expresión de sus habitantes. Estos no eran simplemente sus pobladores, sino sus constructores. Al crear Villa El Salvador y desarrollarla, se crearon a sí mismos. Por eso, cuando se pregunta a los habitantes de la Villa de dónde son, no contestan como otros llegados del interior, haciendo referencia a su lugar de nacimiento, sino que dicen "soy de Villa", el lugar que les dio una identidad que valoran altamente. El proceso de enfrentar desafíos muy difíciles y avanzar fue asimismo fortaleciendo su autoestima, estímulo fundamental para la acción productiva. Describe Franco: “... cuando se asiste con alguna frecuencia a reuniones de pobladores y se conversa con los 'fundadores' de la comunidad, o sus dirigentes, no resulta difícil advertir expresiones recurrentes de autoconfianza colectiva, certidumbres sobre su disposición de un poder organizado, una cierta creencia en las capacidades de la comunidad para proponerse objetivos y unirse para su logro".

La autoestima fue especialmente cultivada también en las escuelas de la Villa. Los maestros trataron de liberar a los niños de todo sentimiento de inferiori- 
dad derivado de sus condiciones de hijos de familias pobres. Procuraron darles seguridad, que no se sintieran en minusvalía.

El esfuerzo de construcción comunitaria de la Villa El Salvador, realizado en las más difíciles condiciones, fue presidido y orientado por ciertos valores. La población definió su proyecto como la conformación de una comunidad de autogestión participativa. Una visión colectiva centrada en la promoción de valores comunitaristas, de la participación activa y de la autogestión, enmarcó todo el esfuerzo. En 1986 la Villa se convirtió en un municipio. Al estructurarlo se mantuvieron todos los principios anteriores. Así, se estipuló que las decisiones comunales serían la base de las decisiones municipales. Recientemente Villa El Salvador estableció, con la ayuda de varias organizaciones no gubernamentales, del Diario El Comercio y de otras entidades, un sistema destinado a facilitar la participación de los pobladores empleando la informática. En virtud de este sistema, el Concejo Municipal transmite sus sesiones en circuito cerrado a la Villa; en ésta hay terminales de computación, y los habitantes pueden recibir a través de ellos información sobre lo que se va a tratar en dichas sesiones y elementos de juicio al respecto, y pueden hacer llegar al Concejo sus puntos de vista; el Concejo realiza, a través del sistema computacional, referendos continuos sobre las opiniones de los habitantes.

La experiencia de la Villa ha sido reconocida mundialmente, siendo objeto de continuas distinciones. En 1973 la Unesco la premió como una de las más desafiantes experiencias en educación popular; en 1987, las Naciones Unidas la designó Ciudad Mensajera de la Paz, distinguiéndola como promotora ejemplar de formas de vida comunitaria. En 1987 se le otorgó el Premio Príncipe de Asturias, del Rey de España. El Papa Juan Pablo II la visitó especialmente y disertó en Villa El Salvador, destacando sus logros (1985).

En la Villa El Salvador no se logró solucionar los problemas de fondo causantes de la pobreza, que tienen que ver con factores que exceden totalmente el ámbito de esta experiencia y forman parte de los problemas generales del país. Sin embargo, obtuvo avances considerables en comparación con poblaciones pobres, y creó un perfil de sociedad muy particular. La potenciación del capital social desempeñó un papel decisivo en los logros de la Villa. Factores invisibles, silenciosos, que actúan en las entrañas del tejido social, tuvieron aquí una acción positiva constante: entre ellos estaban el fomento permanente de formas de cooperación; la confianza mutua entre los actores organizacionales; la existencia de un comportamiento cívico comunal, constructivo y creador; la presencia de valores comunes orientadores; la movilización de la cultura propia; la afirmación de la identidad personal, familiar y colectiva, y la mayor autoestima emanada de la misma experiencia. Todos estos elementos fueron dinamizados por el modelo genuinamente participativo que adoptó la comunidad.

\section{Las Ferias de consumo familiar de Venezuela: los dividendos del capital social}

La pregunta de cómo abaratar el costo de los productos alimenticios para los sectores humildes de la población ha tenido una respuesta significativa en la ciudad de Barquisimeto, en Venezuela. Iniciadas en 1983, las Ferias de consumo familiar han logrado reducir en un $40 \%$ los precios de venta al público de frutas y hortalizas, y en un 15 al $20 \%$ los precios de los víveres, beneficiando semanalmente a 40000 familias de esa ciudad de un millón de habitantes. Estas familias, principalmente de estratos bajos y medios bajos, obtienen mediante compras en las Ferias un ahorro anual que se estima en 10.5 millones de dólares.

Las Ferias están integradas por un amplio número de organizaciones de la sociedad civil. Formalmente son parte de la Central Cooperativa del Estado Lara (CECOSESELA), pero en su operación intervienen grupos de productores, asociaciones de consumidores y pequeñas empresas autogestionadas. Así, en ellas participan 18 asociaciones de productores agrícolas, que agrupan a cerca de 600 productores, y 12 unidades de producción comunitaria. Esos pequeños y medianos agricultores y los productores de víveres colocan su producción a través de las Ferias. Las Ferias comprenden 50 puntos de ventas, que operan los tres últimos días de la semana, y venden directamente a la población 300 toneladas semanales de productos hortofrutícolas y víveres comunes para el consumo hogareño.

Las Ferias venden, como producto básico, un kilo de productos hortofrutícolas por un precio único, lo que simplifica al máximo su operación. Entre los productos se hallan: papa, tomate, zanahoria, cebolla, pimentón, lechuga, name, ocumo, apio, ayuma, yuca, repollo y plátano. Los hacen llegar a través de sus transportes y locales directamente del pequeño productor al consumidor. Todos salen ganando. El pequeño productor, antes dependiente de "roscas" de la comercialización y de vaivenes continuos, tiene a través de ellas asegurada la venta de su producción a precios razonables, y es uno de los cogestores de toda la iniciativa. A su vez, los consumidores reciben productos frescos a precios mucho más bajos que los del mercado. 
Las Ferias de consumo familiar han crecido rápidamente y se han convertido en el principal proveedor de alimentos y productos básicos de la ciudad de Barquisimeto (cuadro 1).

Como se observa en el cuadro, partiendo de una sola unidad de venta, y casi sin capital inicial, las Ferias han crecido aceleradamente en todos los indicadores considerados. Entre 1990 y 1997 aumentaron en 78\% las toneladas semanales de productos hortofrutícolas vendidos, y se duplicó la cantidad de familias atendidas.

¿Cómo logró este éxito económico y de eficiencia un conjunto de organizaciones de base de la sociedad civil, carentes de capital, que se lanzaron a un mercado de productos agroalimentarios caracterizado por una alta competitividad y escasos márgenes de beneficio?

En la base del éxito parecen hallarse elementos claves del capital social. Los actores de la experiencia señalan como base de sus logros "i) una historia de formación de un capital social y humano; ii) potenciar el capital social por encima del financiero; iii) unas formas novedosas de gestión participativa" (Ferias de Consumo Familiar, 1996).

Los varios centenares de trabajadores que llevan adelante las Ferias y las asociaciones vinculadas a ellas han establecido un sistema organizacional basado en la cooperación, la participación y la horizontalidad, y fuertemente orientado por valores.

Las Ferias tienen tras de ellas una concepción de vida que privilegia, según indican sus actores, la solidaridad, la responsabilidad personal y de grupo, la transparencia en las relaciones, la creación de confianza, la iniciativa personal y el amor al trabajo.

Esta tabla de valores no permanece confinada a alguna declaración escrita, como sucede con frecuen- cia, sino que se trata de cultivar orgánicamente. Un observador externo (Bruni Celli, 1996) describe así la dinámica cotidiana de las ferias: "Los valores cooperativistas de crecimiento personal, apoyo mutuo, solidaridad, frugalidad, y austeridad; de enseñar a otros, de no ser egoísta y dar lo mejor de sí para la comunidad, son temas de reflexión continua en las ocho o más horas de reuniones a las que asisten todos los trabajadores de CECOSESELA a la semana. El alto número de horas dedicadas a reuniones podría verse como una pérdida en productividad, pero son el principal medio a través del cual se logra la dedicación, el entusiasmo y el compromiso de los trabajadores de la organización".

Enmarcado en esos valores, el diseño organizacional adoptado parece haber desempeñado un papel decisivo en los resultados alcanzados. Está centrado en principios como la participación activa de todos los integrantes de la organización, la comunicación fluida, el análisis y el aprendizaje conjuntos, y la rotación continua de tareas. Uno de sus rasgos es que los centenares de trabajadores de la organización ganan igual remuneración (superior al salario mínimo nacional en un 57\%). Además, la organización ha creado un fondo de crédito que presta a tasas bajas, y un fondo integrado de salud. Siendo modesta la remuneración, los miembros de la organización han indicado que tienen otros incentivos, como participar de un proyecto con estos valores, formar parte de un ambiente de trabajo democrático y no autoritario, y tener posibilidades de formación y desarrollo.

Los mecanismos operativos concretos de la organización incluyen: reuniones semanales de cada grupo para evaluar y planificar; toma de decisiones por consenso; información compartida; disciplina y vigilancia colectiva; trabajo descentralizado de cada gru-

Venezuela: Expansión de las Ferias de consumo familiar de Barquisimeto

\begin{tabular}{lrrr}
\hline & 1984 & 1990 \\
\hline Unidades de venta & 1 & $87^{\mathrm{a}}$ \\
Venta semanal de productos hortofrutícolas (en toneladas) & 3 & $105^{\mathrm{b}}$ & 300 \\
Número de familias atendidas & 300 & 15 & 000 \\
Número de trabajadores & 15 & 400 \\
Número de productores agrícolas & 1 & 100 \\
Número de organizaciones de productores & 1 & $\mathrm{~N} / \mathrm{d}$ \\
Número de unidades de producción comunitaria & 500 & 9 \\
\hline
\end{tabular}

Fuente: Gómez Calcano (1998), con datos de CECOSESELA (1990-1997).

a Incluye todo el Estado Lara; aproximadamente la mitad en Barquisimeto.

b Incluye 50 ferias y 55 centros de abastecimiento solidario. 
po, y la mencionada rotación de responsabilidades. A ellos se suman los espacios de encuentro denominados "convivencias", que están dedicados al encuentro personal y social.

Estos rasgos organizacionales coinciden con muchas de las recomendaciones de la gerencia moderna. Son propicios para crear lo que se llama hoy "una organización que aprende", y "una organización inteligente". El modelo organizacional de las Ferias tiene gran flexibilidad; ésta les permite absorber por todos sus "poros" información sobre lo que sucede en la realidad, la que al ser compartida internamente, acrecienta la capacidad de reacción ante los cambios que se producen. Asimismo, permite hacer sobre la marcha el seguimiento de los procesos, detectando rápidamente los errores. El clima de confianza creado entre sus integrantes evita los cuantiosos costos de la desconfianza y el enfrentamiento permanente, muy característicos de otras organizaciones. Por otra parte, los elementos del modelo favorecen un sentimiento profundo de pertenencia que es un estímulo fundamental para la productividad.

Las Ferias han resistido todos los pronósticos de que difícilmente podrían enfrentar los rigores del mercado. Por el contrario, se han posicionado en una situación de liderazgo en el mercado respectivo, obligando a otros competidores empresariales a tratar de ajustar sus precios. Se han convertido en el principal comercializador de alimentos básicos de la cuarta ciudad (en población) de Venezuela y, a pesar de su dimensión local, por las cifras que manejan constituyen una de las principales empresas comercializadoras de alimentos del país entero. Han demostrado ser plenamente sustentables y en 15 años han ido ampliando continuamente sus operaciones.

Actualmente están inspirando imitaciones en diversas ciudades del país. Las claves de la excelencia alcanzada no están, en este caso, en grandes inversiones de capital manejadas con criterios empresariales clásicos de maximización de la rentabilidad, ni en una gerencia vertical. El capital que han movilizado es, esencialmente, "capital social". Han promovido ciertos valores latentes en la sociedad civil; han mostrado la posibilidad de realizar un proyecto colectivo, que es a la vez eficiente desde el punto de vista productivo, socialmente útil, y atractivo como marco de vida, y han potenciado - a través de su particular estilo gerencial, que ellas han denominado de "gestión solidaria"elementos básicos de la concepción aceptada de capital social, como la asociatividad y la confianza mutua, y normas de comportamiento que favorecen lo comunitario.
Analistas locales como Machado y Freites (1994) señalan que, a su vez, se han apoyado en el vasto capital social existente en el estado Lara, el estado venezolano con mayor presencia de organizaciones cooperativas. En 1994 había en él 85 cooperativas, 36 de ellas de servicios múltiples, así como una densa red de organizaciones no gubernamentales (más de 3 500), y numerosas asociaciones de vecinos y otras formas de organización social. Vemos así que en el estado Lara hay todo un hábitat cultural que favorece el desarrollo del capital social y que ha dado pie a una experiencia de estas características.

\section{El presupuesto municipal participativo de Por- to Alegre (Brasil); ampliando el capital social existente}

La experiencia de presupuesto municipal participativo iniciada en la Ciudad de Porto Alegre en 1989, se ha transformado en una experiencia "estrella" a nivel internacional y ha concitado amplísima atención. Cerca de 70 municipios del Brasil están iniciando experiencias similares inspiradas en Porto Alegre.

Este impacto se debe a resultados muy concretos. La ciudad de Porto Alegre, de 1300000 habitantes, adolecía en 1989 de importantes problemas sociales, y amplios sectores de su población tenían limitado acceso a servicios básicos. El cuadro era, asimismo, de penuria aguda de recursos fiscales. El nuevo alcalde electo resolvió invitar a la población a cogestionar el rubro de inversiones del presupuesto municipal. En este caso la invitación no fue mero discurso, sino que se estableció un complejo y elaborado sistema que posibilitaba la participación masiva. La ciudad fue dividida en 16 regiones, en cada una de las cuales se analizan las cifras de ejecución presupuestaria y las estimaciones futuras, y se identifican a nivel de barrio prioridades que luego se van concertando y compatibilizando a nivel regional y global. Junto a las regiones, existe otro mecanismo de análisis y decisión que funciona por grandes temas de preocupación urbana: desarrollo urbano, transporte, atención de la salud, tiempo libre, educación y cultura. En grupos de trabajo, reuniones intermedias, plenarios y otras formas de reunión que se van sucediendo durante todo el año, participan públicos amplios, delegados electos y funcionarios del municipio. El presupuesto que se va conformando de abajo hacia arriba es por último sancionado formalmente por el Concejo Municipal.

La población reaccionó con una "fiebre participativa" — como la llamó Navarro (1998) — a la con- 
vocatoria del alcalde. En 1995 se estimaba que 100000 personas participaban en el proceso.

Los resultados han sido sorprendentes y han echado por tierra los vaticinios pesimistas que veían como una heterodoxia inadmisible la entrega de una cuestión tan técnica y delicada como el presupuesto a un proceso de participación popular. Por un lado, la población determinó sus reales necesidades y reorientó recursos hacia los problemas más sentidos. Por otro, todo el trayecto del presupuesto, otrora impenetrable y cerrado, se abrió totalmente para la ciudadanía. Al compartirse con ella toda la información, ésta se convirtió en transparente, lo que generó condiciones propicias para erradicar toda forma de corrupción. La población, masivamente, hizo el control social de la ejecución y confección de la partida de inversiones, que significó el 15\% del presupuesto total y que en 1989/ 1995 sumó 700 millones de dólares. Asimismo, al existir reglas del juego claras sobre cómo sería el proceso de toma de decisiones, se recortaron al máximo los espacios para prácticas clientelísticas arbitrarias.

La correspondencia del presupuesto con las necesidades prioritarias y la mejora de su administración llevaron a resultados muy significativos. Entre $1990 \mathrm{y}$ 1996 el abastecimiento de agua potable subió de 400000 a 484000 hogares atendidos, cubriéndose así el $98 \%$ de la población. En cuanto al alcantarillado, mientras que en 1989 sólo el 48\% de los hogares estaban conectados a la red de cloacas, en 1997 lo estaba el $80.4 \%$ (el promedio del Brasil era de $49 \%$ ). El programa de legitimación de la propiedad de la tierra en sectores pobres y asentamientos humanos benefició entre 1990 y 1996 a 167408 personas (13\% de la población). La pavimentación de calles alcanzó a 30 $\mathrm{km}$ por año en las áreas pobres de la ciudad. La matrícula en la escuela primaria y secundaria subió en un $159 \%$ entre 1989 y 1997, y el municipio creó un programa de alfabetización de adultos que en 1997 tenía 5277 participantes.

La identificación de prioridades ajustadas a las necesidades reales, y el sistema en su conjunto, habían producido una vasta reasignación de recursos que, sumada a la participación colectiva en el seguimiento de los procesos de ejecución, posibilitaron resultados de esta magnitud. La población se transformó en un gran actor del proceso presupuestario municipal.

La amplia base social de apoyo a cambios presupuestarios profundos se expresó también en una fuerte presión por hacer más progresivo y eficiente el sistema fiscal del municipio, y se realizaron importantes reformas en él que permitieron ampliar la recaudación y mejorar la equidad fiscal.
En su conjunto, cambió apreciablemente la fisonomía política tradicional del municipio, que era semejante a la de muchos otros de la región: hubo una redistribución de funciones entre el municipio y la sociedad civil; esta última se activó enérgicamente; se instalaron formas de democracia directa; se redujo muy fuertemente el margen para la corrupción, al hacerse tan trasparente y vigilado el manejo de las finanzas públicas; surgieron condiciones desfavorables para las prácticas clientilísticas, y se descentralizaron las decisiones.

El proceso descrito se basó en el capital social existente en esa sociedad. Había en ella una tradición relevante de asociaciones de la comunidad. Estas se movilizaron activamente y tuvieron un papel fundamental en los diversos niveles de deliberación creados. Como señala Navarro, un eje decisivo fue la voluntad política del alcalde de superar los esquemas habituales de concentración del poder y convocar a la población y a dichas asociaciones a "compartir el poder". Ese llamado y el establecimiento de mecanismos de participación genuinos actuaron como ampliadores del capital social. Se disparó la capacidad de cooperación, se creó un clima de confianza entre los actores y se generaron fuertes estímulos para un comportamiento cívico constructivo. La cultura asociativa preexistente fue un cimiento esencial para que la población participara, y a su vez se vió fortalecida enormemente por el proceso. Este último mostró las potencialidades que aparecen cuando se superan las falsas oposiciones entre Estado y sociedad civil y se produce una alianza entre ambos.

En Porto Alegre, el capital social se comportó de acuerdo a las previsiones de Hirschman (1984), señaladas más atrás. $\mathrm{Al}$ dársele un uso intensivo, creció. Lo señala el BID (1997), al destacar que el proceso participativo "... ha tenido un enorme impacto en la habilidad de los ciudadanos para responder a los retos organizadamente, como comunidad, y en la capacidad de trabajar en forma conjunta para mejorar la calidad de la administración pública y, en consecuencia, la calidad de la vida".

\section{Algunas enseñanzas de las experiencias des- critas}

Las experiencias reseñadas han tenido efectos importantes, han demostrado fuerte sustentabilidad y han alcanzado múltiples reconocimientos. ¿Cuáles han sido las claves de su éxito? Aunque se han desarrollado en medios muy diferentes, es posible encontrar algunos 
elementos comunes a todas ellas que han influido significativamente en sus resultados.

En primer lugar, las estrategias utilizadas se han basado en el aprovechamiento de formas de capital no tradicional. Se promovió la puesta en acción de fuerzas latentes en los grupos sociales. En todas las experiencias se puso en juego la capacidad de buscar respuestas y ejecutarlas cooperativamente; se creó un clima de confianza entre los actores; se partió de sus culturas, respetándolas cabalmente y estimulando su desarrollo y se fomentó un estilo de conducta cívica solidario y atento al bienestar general. El estímulo a estos factores y a otros semejantes creó energías comunitarias y organizacionales que pudieron llevar adelante amplios procesos de construcción, partiendo de la miseria en Villa El Salvador, de recursos ínfimos en las Ferias de Barquisimeto, y de recursos limitados y déficit en Porto Alegre.

Un segundo rasgo común es la adopción de un diseño de organización totalmente no tradicional. En los tres casos la base de ese diseño fue la participación organizada de la comunidad. En un trabajo reciente (Kliksberg, 1998) analizamos en detalle las posibilidades organizacionales de la participación. Allí señalamos, sobre la base del análisis de experiencias internacionales comparadas y de una amplia información empírica, que la participación tiene importantes ventajas competitivas sobre los diseños jerárquicos usuales, e identificamos los mecanismos a través de los cuales se generan dichas ventajas. Por otra parte, la participación es hoy parte esencial de los modelos de gestión de las organizaciones más avanzadas del mundo.

Un tercer elemento distintivo de las tres experiencias es, que tras la movilización del capital social y la cultura y de los diseños de gestión abierta y democrática, hubo una concepción valórica que fue decisiva.
Sin ella no se hubieran podido resolver las múltiples dificultades del camino innovativo - y no tradicional- que se siguió. Los valores sustentados sirvieron de orientación continua y a la vez motivaron poderosamente el comportamiento de las comunidades y transmitieron la visión inspiradora de las metas finales hacia las que se dirigían los esfuerzos.

En la región se están desarrollando otras experiencias, que con sus especificidades, siguen total o parcialmente rasgos como los delineados, y les agregan otros. Sus resultados son muy importantes. Entre muchas otras, se hallan el programa educo, en El Salvador, basado en la autoorganización de familias campesinas pobres para la gestión de escuelas rurales; los programas de Vaso de Leche en Perú; el papel de las comunidades indígenas organizadas en Bolivia y Ecuador, y la participación de los padres en el manejo de las escuelas en Minas Gerais.

Se podrá argüir, como se ha hecho, que experiencias de este orden tienen un alcance limitado. Sin embargo, la realidad muestra que, si bien encuentran dificultades considerables y no son extensibles con facilidad, hacen aportes formidables: mejoran directamente la calidad de vida de amplios sectores desfavorecidos, son un laboratorio de formas sociales avanzadas, e implican un llamado motivante a avanzar en esa dirección

En definitiva, movilizar el capital social y la cultura como agentes activos del desarrollo económico y social no constituye por sí sola una propuesta utópica; es viable y da resultados efectivos. Hay referencias significativas en las cuales apoyarse. Para llevar a cabo esa movilización en escala considerable —un gran desafío hacia el futuro- - se necesitarán políticas orgánicas y amplias concertaciones entre el Estado y la sociedad civil.

\section{IV}

\section{Hora de movilizar el potencial de la cultura}

La actividad cultural ha sido vista con frecuencia, desde la economía, como un campo secundario ajeno a la vía central por la que debería hacerse avanzar el crecimiento económico. Con frecuencia se la ha tratado de hecho como un área que insume recursos, que no genera retornos económicos a la inversión, cuyos productos son difíciles de medir, y cuya gestión es de du- dosa calidad. A su vez, en el ámbito de la cultura también ha existido cierta tendencia al autoencierro y a no buscar activamente conexiones con los programas económicos y sociales, lo que ha creado una brecha considerable entre cultura y desarrollo. Esta situación acarrea grandes pérdidas para la sociedad: obstaculiza seriamente el avance de la cultura, que pasa a ser trata- 
da como un aspecto secundario y de "puro gasto", y al mismo tiempo tiene un gran costo de oportunidad, ya que no emplea los posibles aportes de la cultura a los procesos de desarrollo.

Para superar la brecha descrita es preciso emprender esfuerzos sistemáticos. La cultura es parte importante del capital social, como lo indican tanto las experiencias reseñadas como otras muchas en curso. La crisis del pensamiento económico convencional abre una oportunidad para que, en la búsqueda de una visión más amplia e integral del desarrollo, se incorporen en plena legitimidad las dimensiones culturales de éste.

Antes de explorar algunas de las intersecciones posibles, una advertencia de fondo. La cultura puede ser un instrumento formidable de progreso económico y social. Sin embargo, allí no se agota su identidad. No es un mero instrumento. El desarrollo cultural de las sociedades es un fin en sí mismo, y avanzar en este campo significa enriquecer espiritual e históricamente a una sociedad y a sus individuos. Como lo subraya el Informe de la Comisión Mundial de Cultura y Desarrollo (Unesco, 1996): "es un fin deseable en sí mismo porque da sentido a nuestra existencia". Esa perspectiva no debe perderse.

Una reconocida economista, Françoise Benhamou formula al respecto algunas prevenciones. Señala: "En realidad, sólo en aras de un economicismo a ultranza, se puede pretender justificar el gasto cultural en función de los recursos tangibles que este puede generar como contrapartida. Las ganancias que la vida cultural le puede aportar a la colectividad, no siempre cubren los gastos ocasionados. Evidentemente, el interés de estos gastos debe ser evaluado en función de otros criterios, que van más allá de la dimensión económica". Reclama criterios diferentes para medir el "rendimiento" de algo que es, en definitiva, uno de los fines últimos de la sociedad. Advierte sobre la aplicación mecánica de criterios usualmente empleados en el campo económico, y las consecuencias "fáciles" y erradas que pueden extraerse de ellos. Destaca: "Sería lamentable que en momentos en que las ciencias de la economía reconocen el valor de la dimensión cualitativa del objeto que están evaluando, los economistas se empeñen en tomar en cuenta solamente las repercusiones comerciales de la inversión cultural. ¿Hay que quejarse del costo de la vida cultural que, en definitiva, es realmente modesto? ¿No habrá que ver en él, el símbolo de una nación adulta y próspera?" (Benhamou, 1997).

Junto a ser un fin en sí misma, la cultura tiene amplísimas potencialidades que pueden movilizarse para el desarrollo. Entre ellas se hallan las que se presentan sumariamente, a continuación.

\section{Cultura y políticas sociales}

La movilización cultural puede ser muy valiosa en la lucha contra la pobreza que hoy aflige a cerca de la mitad de los habitantes de la región. Los elementos intangibles subyacentes en la cultura pueden cooperar de múltiples modos.

Los grupos pobres no tienen riquezas materiales, pero sí tienen un bagaje cultural, a veces de siglos o milenios, como el de las poblaciones indígenas. El respeto profundo por su cultura creará condiciones favorables para hacer uso, en el marco de los programas sociales, de saberes acumulados, tradiciones, modos de vincularse con la naturaleza y capacidades culturales naturales para la autoorganización, que pueden tener gran utilidad.

Por otra parte, la consideración y valoración de la cultura de los sectores desfavorecidos es un punto clave en el tema crucial de la identidad colectiva y la autoestima. Con frecuencia la marginalidad y la pobreza económicas van acompañadas por desvalorizaciones culturales. La cultura de los pobres es estigmatizada por sectores de la sociedad como inferior, precaria, atrasada. Se achacan incluso, "alegremente", a pautas de esa cultura las razones mismas de la pobreza. Los pobres sienten que, además de sus dificultades materiales, enfrentan un proceso silencioso de "desprecio cultural" hacia sus valores, tradiciones, saberes, formas de relación. Al desvalorizar su cultura se está en definitiva debilitando su identidad y una identidad golpeada genera sentimientos colectivos e individuales de baja autoestima.

Las políticas sociales deberían tener como objetivo importante la reversión de este proceso y la elevación de la autoestima colectiva y personal de las poblaciones desfavorecidas. Una autoestima fortalecida puede ser un potente motor de construcción y creatividad. La mediación imprescindible es la cultura. La promoción de la cultura popular, la apertura de canales para su expresión, su cultivo en las generaciones jóvenes, la creación de un clima de aprecio genuino por sus contenidos, hará crecer la cultura y con ello devolverá identidad a los grupos empobrecidos.

En América Latina hay interesantes experiencias de este orden. Entre ellas, la pujante actividad de formación de coros y conjuntos musicales populares realizada en Venezuela en las últimas décadas. En virtud de un trabajo sostenido se conformaron en distintas comunidades, muchas de ellas pobres, conjuntos que 
aglutinaron a miles de niños y jóvenes en derredor, principalmente, de temas de la cultura popular. Estos espacios culturales, al mismo tiempo que permitían expresarse y crecer artísticamente a sus miembros, les transmitían amor y valoración por su cultura y fortalecían su identidad. Asimismo, tenían efectos no previstos. La práctica sistemática de estas actividades fomentaba, de hecho, hábitos de disciplina, culto por el trabajo y cooperación. Similares experiencias tuvieron lugar en gran escala, en períodos recientes, en Colombia y otros países.

\section{Cultura e integración social}

Uno de los problemas básicos de las sociedades latinoamericanas es la exclusión social, que dificulta severamente el acceso de algunos sectores a los mercados de trabajo y de consumo, y les hace imposible incorporarse a marcos de integración de la sociedad. Estos obstáculos se refuerzan unos a otros, configurando círculos perversos regresivos.

La democratización de la cultura puede romper estos círculos en un aspecto de importancia. La creación de espacios culturales asequibles a los sectores desfavorecidos y estimulados especialmente puede crear canales de integracion inéditos.

La cultura puede, asimismo, reforzar significativamente el capital educativo de las poblaciones pobres. La región se caracteriza por altas tasas de deserción y repetición de dichas poblaciones en la escuela primaria (cerca de la mitad de los niños abandona la escuela antes de completar seis grados). Es preciso desplegar todos los esfuerzos posibles para mejorar esta situación. Pero, al mismo tiempo, las actividades culturales pueden funcionar como un parasistema educativo, ofreciendo posibilidades de formación informal que complementen y refuercen la escuela. Esto sería especialmente valioso para los numerosos adultos que desertaron de la escuela en su juventud.

La cultura puede ser un marco de integración atractivo y concreto para los vastos contingentes de jóvenes latinoamericanos que se hallan actualmente fuera del mercado de trabajo y que no están en el sistema educativo, constituyendo de hecho una población muy expuesta a caer en la delincuencia. Los análisis sobre el gran aumento de la criminalidad en la región en las últimas décadas, indican que un porcentaje creciente de los delincuentes es joven y responde a un perfil de desocupación y limitada educación. En los espacios culturales puede darse a esta población alternativas de pertenencia social y crecimiento personal.
La cultura puede contribuir de manera efectiva a la institución más básica de integración social, la familia. Investigaciones de los últimos años dan cuenta de que, junto a su decisivo rol afectivo y espiritual, la familia tiene un influjo muy destacado en muchas otras áreas. Influye fuertemente en el rendimiento educativo de los niños, en la formación de la creatividad y la capacidad de crítica, en el desarrollo de la inteligencia emocional, en la adquisición de una cultura de salud preventiva. Es, al mismo tiempo, una de las principales redes de protección social y el marco primario fundamental de integración social.

En América Latina, ante el impacto de la pobreza, numerosas familias de las áreas humildes de la sociedad se han tensado al máximo y están en crisis. Se estima que más del $20 \%$ de las familias de la región son unidades con sólo la madre al frente. En la gran mayoría de los casos se trata de familias de escasos recursos. Asimismo, han aumentado los hijos extramatrimoniales, indicador de la renuencia de las parejas jóvenes a formar familias estables, en muchos casos debido a las dificultades económicas para sostenerlas.

Los espacios culturales pueden ayudar a fortalecer esta institución eje de la sociedad, que hace incalculables aportes a ella. La actividad conjunta de los miembros de la familia en dichos espacios puede hacer más sólidos los lazos. Asimismo, en ellos las familias pueden encontrar estímulos y respuestas, enriquecer sus realidades y compartir experiencias con otras unidades familiares enfrentadas a problemas similares.

\section{Cultura y valores}

A los valores de una cultura se les asigna un peso decisivo en el desarrollo. En años recientes, se ha discutido largamente sobre el tipo de valores que han ayudado a países que exhiben un crecimiento sostenido y logros sociales significativos.

Si los valores dominantes se concentran en el individualismo, la indiferencia frente al destino del otro, la falta de responsabilidad colectiva, el desinterés por el bienestar general, la búsqueda del enriquecimiento personal como valor central, el consumismo y otros semejantes, cabe esperar que las conductas consiguientes debiliten seriamente el tejido social y conduzcan a todo orden de efectos regresivos: desde fuertes inequidades económicas que, según indican múltiples investigaciones, generan poderosas trabas a un desarrollo económico sostenido, hasta descensos en la cohesión 
social que pueden, incluso, afectar la esperanza de vida media. ${ }^{1}$ Uno de los efectos visibles de la vigencia de valores antisolidarios, es la extensión de la corrupción en diversas sociedades. Como lo resalta Arizpe (1998): "La insistencia monotemática de que enriquecerse es lo único que vale la pena en la vida, ha contribuido en gran medida a esa tendencia”.

Los valores positivos, en cambio, conducen a direcciones diferentes. Así, por ejemplo, las sociedades que han estimulado y cultivado valores favorables a la equidad y los han reflejado en sus sistemas fiscales, en la universalizacion de los servicios de salud y de una educación de buena calidad, tienen actualmente buenos niveles en esos ámbitos, los que a su vez facilitan su progreso económico y tecnológico y su competitividad. Como casos ilustrativos suelen mencionarse los países nórdicos, Canadá, Japón e Israel, entre otros.

La cultura es el ámbito básico en que una sociedad genera valores y los transmite de generación en generación. En América Latina, promover y difundir sistemáticamente valores como la solidaridad (de profundas raíces en las culturas indígenas autóctonas), la cooperación, la responsabilidad de los unos por los otros, el cuidado conjunto del bienestar colectivo, la superación de las discriminaciones, la erradicación de la corrupción, la democratización ${ }^{2}$ y la búsqueda de una mayor equidad (en una región tan marcadamente desigual), claramente ayudará al desarrollo además de contribuir a conformar el perfil de la sociedad.

Son notables, al respecto, los resultados alcanzados por sociedades que han cultivado consistentemente la acción voluntaria en las nuevas generaciones. La acción voluntaria recoge muchos de los valores antes mencionados. Tiene un gran valor educativo, produce resultados económicos de importancia al añadir horas de trabajo sin salario a programas valiosos para la sociedad, y promueve sentimientos de solidaridad y cooperación. En diversos países los voluntarios constituyen un porcentaje significativo de la fuerza de trabajo total del sector social; su actividad es valorada por

\footnotetext{
1 Véase una investigación pionera sobre la incidencia de los valores en la vida cotidiana y el tejido social chilenos en PNUD (1998a). Este trabajo explora el mundo interno de las personas y la calidad de sus relaciones con los otros, hace hallazgos de gran relevancia en términos de capital social, cultura y problemas de desarrollo, e identifica un extenso malestar social en la sociedad chilena ligado, entre otros aspectos, al debilitamiento de las interrelaciones.

${ }^{2}$ Al respecto véanse los trabajos del Proyecto Regional Cultura y Democracia conducido por Saul Sosnowsky, director del Instituto de Estudios Latinoamericanos de la Universidad de Maryland.
}

toda la sociedad y constituye una posibilidad de atraer a numerosos jóvenes. Hay amplios contingentes de voluntarios, por ejemplo, en los países nórdicos, Canadá, varios países de Europa occidental e Israel. Faigon (1994) indica que un 25\% de la población de Israel realiza tareas voluntarias de modo regular, particularmente en el campo social, y genera bienes y servicios equivalentes al $8 \%$ del producto interno bruto; subraya que las bases de estos resultados se hallan en la cultura judía, que jerarquiza el servicio voluntario a la comunidad como un deber, y en la inculcación sistemática de valores solidarios en los marcos de la escuela israelí.

El cultivo de los valores a través de la cultura y la participación desde los primeros años en actividades voluntarias y tareas comunitarias, influye considerablemente en la adquisición de compromisos cívicos en las edades adultas, según concluyen Youniss, McLellan y Yates (1997) sobre la base de investigaciones recientes. Se observa una correlación estadística entre haber actuado en organizaciones en los años jóvenes, e involucrarse en la sociedad en épocas posteriores. Así, un estudio efectuado en Estados Unidos muestra que quienes habían sido miembros de clubes 4H tenían, 25 años después, el doble de probabilidades de estar integrando asociaciones cívicas que quienes no habían pasado por esos clubes, y una probabilidad cuatro veces mayor de estar participando en política. Otro estudio sobre graduados de escuelas secundarias mostró que, 15 años después, los que habían participado en actividades extracurriculares en la escuela tenían mayores probabilidades de estar participando en asociaciones voluntarias. Los valores y la participación van moldeando lo que los autores llaman una "identidad cívica" orientada a asumir compromisos con la comunidad y aportar continuamente a ella.

Una interesante experiencia encaminada a promover valores culturales útiles para la sociedad se inició hace poco en Noruega. El 30 de enero de 1998 dicho país estableció la Comisión Gubernamental de Valores Humanos, con tres finalidades centrales: i) crear en la sociedad conciencia cada vez mayor de los valores y los problemas éticos; ii) contribuir a un mayor conocimiento del desarrollo de valores humanos en nuestra cultura contemporánea; iii) identificar desafíos éticos actuales en la sociedad y esbozar posibles respuestas, y iv) estimular a los diferentes sectores de la sociedad a incorporarse a este debate.

Los integrantes de la Comisión proceden de diversos sectores sociales y pertenecen a diferentes generaciones. Sus actividades apuntan a que el tema valórico esté en el centro de la agenda pública y sea 
analizado por las instituciones tanto públicas como privadas, a que se identifiquen y planteen explícitamente los dilemas éticos, y a que se busquen respuestas para ellos. Entre las primeras iniciativas que puso en marcha la Comisión se halla la de que todas las escuelas del país examinen cómo se están aplicando en el ámbito local los derechos proclamados en la Declaración de los Derechos Humanos de las Naciones Unidas. También está impulsando estudios a nivel municipal -está descentralizando muchas de sus acciones- sobre las tensiones que sufren niños y jóvenes por la frecuente contradicción entre los valores impartidos en el hogar, la escuela y la iglesia, y los que les llegan por los medios de comunicación. Otro proyecto busca crear mayor conciencia en materia de responsabilidad, solidaridad y participación. Y otro invitó a los alcaldes de los municipios del país a iniciar un proceso deliberativo en el ámbito local, para establecer cuáles son los rasgos básicos de una buena comunidad local.

Las potencialidades culturales de América Latina - que son inmensas, como lo demuestra su fecundidad en tantos campos artísticos — pueden materializarse en importantes aportes a la lucha contra la pobreza, el desarrollo de la integración social, el fortalecimiento de valores comunitarios, solidarios y participativos, y otras áreas. Para movilizar esas potencialidades se requiere una acción concertada entre el Estado y las organizaciones de la sociedad civil, que deben coordinar esfuerzos y aportar lo mejor que puedan contribuir para, en conjunto, liberar las ingentes fuerzas de creatividad cultural popular latentes en la región.

Hay serias falencias en América Latina en esta materia. Junto a grandes esfuerzos de algunos sectores por promover la cultura y lograr importantes concreciones, se observan reservas y marginaciones por parte de otros ante la tarea de incorporar la cultura a la agenda central del desarrollo. Se le restan recursos, se la hace objeto preferente de recortes presupuestarios, y se la somete a continuos cambios que le restan la estabilidad necesaria para asentar actividades e instituciones. Se suele argumentar, asimismo que la cultura sería una especie de necesidad secundaria que tendría su lugar cuando otras previas se hubieran satisfecho. Se llega, en algunos casos, a la situación tan bien descrita por Pierre Bourdieu: “... la ausencia de cultura se acompaña, generalmente, de la ausencia del sentimiento de esta ausencia". 3

Por estos razonamientos y prácticas se está dejando de utilizar una de las grandes fuerzas para efectuar cambios profundos en las realidades de un continente que enfrenta tan difíciles desafíos en campos que afectan decisivamente la vida cotidiana de las personas, como la pobreza y la inequidad. ${ }^{4} \mathrm{Ha}$ llegado la hora de superarlos y de explorar activamente los múltiples aportes que la cultura puede hacer al desarrollo.

\section{Bibliografía}

Arizpe, L. (1998): La cultura como contexto del desarrollo, en L. Emmerij y J. Núñez del Arco (comps.), El desarrollo económico y social en los umbrales del siglo XXI, BID, Washington D.C.

Baas, S. (1997): Participatory institutional development, trabajo presentado a la Conference on Sustainable Agriculture and Sand Control in Gansu Desert Area, http://www. worldbank.org/ poverty/a capital/index.htm.

Benhamou, F. (1997): Economía de la cultura, Montevideo, Ediciones Trilce.

BID (Banco Interamericano de Desarrollo) (1997): Libro de consulta sobre participación, Washington, D.C.

Bruni Celli, J. (1996): Las Ferias de consumo familiar de Barquisimeto, Caracas.

Bullen, P. y J. Onyx (1998): Measuring social capital in five communities in New South Wales, Working paper series, $\mathrm{N}^{\circ} 41$, Sydney, Australia, University of Technology, Center for Australian Community Organizations and Management (CACOM).

Chang, H.N. (1997): Democracy, diversity and social capital, National Civic Review, vol. 86, $\mathrm{N}^{\circ} 2$, San Fernando, California.

Chile, Presidencia de la República (1998): Declaración de Santiago, II Cumbre de Las Américas, Santiago de Chile.
Coleman, J. (1990): Foundations of Social Theory. Cambridge, Massachusetts, Harvard University Press.

Faigon, Y. (1994): El voluntarismo en la sociedad israelí, trabajo presentado al Encuentro BID-Congreso Judío Latinoamericano. La lucha contra la pobreza a fines del siglo XX, Washington, D.C., Banco Interamericano de Desarrollo.

Ferias de consumo familiar de Barquisimeto (1996): La experiencia de las Ferias, Venezuela, mimeo.

Franco, C. (1992): Imágenes de Villa El Salvador, B. Kliksberg, comp., ¿Cómo enfrentar la pobreza? Aportes para la acción, Buenos Aires, Grupo Editor Latinoamericano.

Fuentes, M.L. (1998): Chiapas: el capital social perdido, México, D.F.

Gómez Cálcano, L. (1996): Las Ferias de consumo familiar del estado Lara, Venezuela. Una experiencia de organización participativa, trabajo presentado al Seminario Programas sociales, pobreza y participación ciudadana, Cartagena, BID.

\footnotetext{
${ }^{3}$ Citado en Benhamou (1997).

${ }^{4}$ Véase varios trabajos recientes sobre las nuevas formas de pobreza en América Latina en Kliksberg, comp. (1993). El tema de la inequidad se explora detalladamente en Kliksberg (1999).
} 
Hagan, J., R. MacMillan y B. Wheaton (1996): New kid in town: Social capital and the life course effects of family migration on children, American Sociological Review, vol. 61, $\mathrm{N}^{\circ} 3$, Washington, D.C., American Sociological Association.

Hirschman, A.O. (1984): Against parsimony: Three easy ways of complicating some categories of economic discourse, The American Economic Review, Vol. 74, $\mathrm{N}^{\circ} 2$, Nashville, Tennessee, American Economic Association.

Iglesias, E. (1997a): Cultura, educación y desarrollo, trabajo presentado en la Asamblea General de la Unesco, París, Organización de las Naciones Unidas para la Educación, la Ciencia y la Cultura.

(1997b): Prefacio, en L. Emmerij y J. Núñez del Arco (comps.), El desarrollo económico y social en los umbrales del siglo XXI, Washington, D.C., BID.

Jonsson, J.O. y M. Gahler (1997): Family dissolution, family reconstitution, and children's educational careers: Recent evidence of Sweden, Demography, vol. 34, $\mathrm{N}^{\circ}$ 2, Madison, Wisconsin, University of Wisconsin, Center for Demography and Ecology.

Joseph, J. (1998): Address: Democracy's social capital: civil society in a new era, Pretoria, Sudáfrica, 15 de enero, http.//www. worldbank.org/poverty/acapital/index.htm.

Kawachi, I., B. Kennedy y K. Lochner (1997): Long live community. Social capital as public health, The American Prospect, $N^{\circ} 35$, Cambridge, Massachusetts, noviembre-diciembre.

Kaztman, R. (1997): Marginalidad e integración social en el Uruguay, Revista de la CEPAL, N 62, LC/G.1969-P, Santiago de Chile, CEPAL.

Kliksberg, B. (1998): Seis tesis no convencionales sobre participación, Revista instituciones y desarrollo, Barcelona. Programa de las Naciones Unidas para el Desarrollo (PNUD), Red de Gobernabilidad y Desarrollo Institucional.

(1999): Desigualdad y desarrollo en América Latina. El debate postergado, Reforma y democracia, $\mathrm{N}^{\circ} 14$, Caracas, Centro Latinoamericano de Administración para el Desarro1lo (CLAD)

Kliksberg, B., comp. (1997): Pobreza. Un tema impostergable. Nuevas respuestas a nivel mundial, México, D.F., Fondo de Cultura Económica (FCE).

Knack, S. y P. Keefer (1997): Does social capital have an economic payoff? A cross country Investigation, Quarterly Journal of Economics, vol. CXII, $\mathrm{N}^{\circ} 4$, Cambridge, Massachusetts, The MIT Press.

La Porta, R., F. López de Silanes, A. Shleifer y R. Vishny (1997): Trust in large organizations, The American Economic Review, vol. 87, $\mathrm{N}^{\circ}$ 2, Nashville, Tennessee, American Economic Association.

Levi, M. (1996): Social and unsocial capital: A review essay of Robert Putnam's "Making democracy work", Politics \& Society, vol. 24, $\mathrm{N}^{\circ} 1$, Los Altos, California, marzo.

Machado, G. y N. Freites (1994): Experiencias exitosas de gestión social en Lara, B. Kliksberg (comp.), El Desarrollo humano en Venezuela, Caracas, Editorial Monte Avila.

Morin, E. (1991): Un noveau commencement, París, Editions du Seuil.

Moser, C. (1998): The asset vulnerability framework: reassessing urban poverty reduction strategies, World Development, vol. 26, No.1, Oxford, Reino Unido, Pergamon Press.

Navarro, Z. (1998): La democracia afirmativa y el desarrollo redistributivo: el caso del presupuesto participativo en Porto Ale- gre, Brasil (1989-1998), trabajo presentado al Seminario Programas sociales, pobreza y participación ciudadana, Cartagena, BID.

Narayan, D. y L. Pritchett (1997): Cents and Sociability. Household Income and Social Capital in Rural Tanzania, Washington, D.C., Banco Mundial.

Newton, K. (1997): Social capital and democracy, American Behavioral Scientist, vol. 40, $\mathrm{N}^{\circ}$ 5, Princeton, New Jersey, marzo-abril.

PNUD (Programa de las Naciones Unidas para el Desarrollo) (1998): Desarrollo humano en Chile1998a, Santiago de Chile, PNUD. (1998b): Desarrollo humano, Informe 1998, Bogotá, Tercer Mundo Editores.

Prigogine, I. (1993): ¿Tan sólo una ilusión? Una exploración del caos al orden, Barcelona, España, Tusquets Editores.

Putnam, R. (1994): Para hacer que la democracia funcione., Caracas, Editorial Galac.

Rupp, J. C. (1997): Rethinking cultural and economic capital. Reworking class, Nueva York, Cornell University Press.

Sanders J. M. y V. Nee (1996): Immigrant self-employment: The family as social capital and the value of human capital, American Sociological Review, vol. 61, No. 2, Washington D.C., American Sociological Association.

Sen, A. (1997a): Economics, business principles and moral sentiments, The Journal of the Society for Business Ethics, vol. 7, $\mathrm{N}^{\circ}$ 3, Chicago, Illinois, Loyola University.

(1997b): Teoría del desarrollo a principios del Siglo XXI, L. Emmerij, y J. Núñez del Arco, (comps.). El desarrollo económico y social en los umbrales del siglo XXI, Washington, D.C., BID.

Serageldin, I. (1998): The Initiative on Defining, Monitoring and Measuring Social Capital: Overview, and Program Description, Social capital initiative working paper, $\mathrm{N}^{\circ} 1$, Washington, D.C., Banco Mundial.

S.S. Juan Pablo II. (1996): Palabras en su visita a Villa El Salvador, 5 de febrero de 1985.

Stiglitz, J. (1998): Más instrumentos y metas más amplias: desde Washington hasta Santiago, Washington, D.C., Banco Mundial.

Teachman, J. D., K. Paasch y K. Carver (1997): Social capital and the generation of human capital. Social Forces, vol. 75, $\mathrm{N}^{\circ} 4$, Chepall Hill, North Carolina, University of North Carolina, junio.

Touraine, A. (1997): Por una nueva política social, El País, Montevideo, 4 de agosto.

UNESCO (1996): Nuestra diversidad creativa, informe de la Comisión Mundial de Cultura y Desarrollo, París.

Wall, E., G. Ferrazzi y F. Schryer (1998): Getting the goods on social capital, Rural Sociology, vol. 63, $\mathrm{N}^{\circ} 2$, Pennsylvania, The Pennsylvania University.

Wilson, J. (1994): Los valores familiares y el papel de la mujer, Facetas, $\mathrm{N}^{\circ}$ 1, Washington, D.C.

Wolfensohn, J. D. (1996: El gasto social es clave, Clarín, Buenos Aires, 26 de febrero.

Youniss, J., J.A. McLellan y M. Yates (1997): What we know about engendering civic identity, American Behavioral Scientist, Princeton, New Jersey, marzo-abril.

Zapata, A. V. (1996): Entrevista a Michel Azcueta, Sociedad y poder local. La comunidad de Villa El Salvador 1971-1996, Lima, DESCO. 